\title{
Sozial Gegenläufiges
}

Liebe Leserinnen, liebe Leser,

der Datenschutz schützt die Menschenwürde, einen ethischen Wert von höchstem Rang. Aber wenn der Mensch feststellt, dass sein Bankkonto von einem Unbekannten geplündert wurde, fällt ihm nicht als erstes die Menschenwürde ein. Vielmehr erschrickt er oder flucht und ruft nach dem Datenschutz. Nicht wegen der verletzten Menschenwürde, sondern wegen des verlorenen Geldes. Es geht ihm um wirtschaftliche Interessen. Sie stehen zwar als ethischer Wert deutlich hinter der Menschenwürde zurück, aber sie beschäftigen bezifferbar den Datenschutz. Wirtschaftliche Interessen markieren auch dessen historischen Anfänge: Die Verweigerung von Krediten an falsch beurteilte Verbraucher hatte 1970 in Amerika zum Fair Credit Reportimg Act geführt. Damit ging die Datenschutzdiskussion an.

Der Datenschutz konkretisiert sich zumeist an Banalem, aber er will auch die Menschwürde schützen. „Schutz der Menschenwürde“ ist ein überzeugungsstarkes Argument. Wer kann auch etwas dagegen haben? Aber wie sehr sie auch das Edle im Menschen ansprechen mag: Sie ist ein Minimalwert, etwas, was auch dem abscheulichsten Menschen zusteht. Jedem Scheusal verbleibt als Letztes noch die Menschenwürde. Unsereiner, der sich gesellschaftsverträglich verhält, meint, an Schutzwürdigem mehr als die nackte Menschwürde vorweisen zu können, und erwartet sich entsprechend mehr vom Datenschutz. Da sind zunächst die wirtschaftlichen Interessen, doch stehen daneben auch ethisch höher geschätzte Werte im Schutz. Walter von der Vogelweide' nennt dazu "driu dinc", die dem Menschen wichtig sind: „êre“, "varnde guot ${ }^{\prime 2}$ und "gotes hulde". Unter den irdischen Gütern ist ihm demnach die Ehre das wichtigste. Danach kommt „varnde guot", der Besitz. Beides, insbesondere aber die Ehre, verstehen sich in der Hinwendung des Dichters an die ritterliche Gesellschaft und deren Quell aller Ehren, den Kaiser.

Es gab auch später Zeiten, da war die Ehre immerhin so wichtig, dass man ihren Verlust nur mit Blut wettmachen konnte. Allerdings galt dies nur unter Begüterten. Der Besitz war dafür Vorraussetzung. In einem Lied des 17. Jahrhunderts heißt es: "Wer jetzig Zeiten leben will, muss han ein tapfres Herze“" und weiter:„Da heißt es stehen ganz unverzagt in seiner blanken Wehre, dass sich der Feind nicht an uns wagt; es geht um Gut und Ehre". Demnach gelten die beiden irdischen Werte Walters noch, aber ihre Reihenfolge hat sich verkehrt. Es geht nun vorrangig um den Besitz. Die Ehre, an zweiter Stelle stehend, verdient es immerhin, mit der blanken Wehre verteidigt zu werden. So weit Geschichtliches zu Gut und Ehre.

Wie, liebe Leserinnen und Leser, steht es heute um die Ehre? Ich meine: Trotz der vielen Ehrungen nimmt sich „Ehre" etwas antiquiert aus. Wenn feierlich, spricht man lieber von der "Menschenwürde" (siehe oben); wenn weniger feierlich, von "Ansehen" oder "Beliebtheit". Insoweit ist sie noch da, die Ehre. Doch sind Werte dazu gekommen, für die ich in der Geschichte keine deutliche Entsprechung finde: Anonymität, Respekt vor der Privatsphäre, Schutz vor Belästigung und öffentlicher Neugier. Das Besondere an diesen neuen, vom Datenschutz geschützten Werten ist: Im Gegensatz zu der eine Hinwendung zur Gemeinschaft erfordernden Ehre folgen sie einer vom Individuum frei gewählten Abwendung von der Gemeinschaft. Hinwendung und Abwendung: Der Datenschutz schützt sozial Gegenläufiges.

\section{Mit freundlichen Grüßen, Ihr}

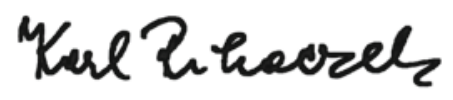

\footnotetext{
1 Walter von der Vogelweide, Reichston, Erster Spruch, "Ich saz uf eime steine .... .

2 "Varnde guot“ meint nicht allein den beweglichen Besitz, sondern auch Immobilien. Von der Huld Gottes sagt Walter, dass sie mehr als die beiden anderen gelte. Sie ist aber uns Heutigen als transzendentes Gut mit Ehre und Besitz nicht vergleichbar.
} 